\title{
Metformin Potentiates the Benefits of Dietary Restraint: A Metabolomic Study
}

\author{
Marta Riera-Borrull 1,2, Anabel García-Heredia 1 (D), Salvador Fernández-Arroyo 1,3 (D), \\ Anna Hernández-Aguilera ${ }^{1}$ (D) , Noemí Cabré ${ }^{1}$, Elisabet Cuyàs ${ }^{3,4}$, Fedra Luciano-Mateo ${ }^{1}$, \\ Jordi Camps ${ }^{1}$, Javier A. Menendez ${ }^{3,4}$ and Jorge Joven ${ }^{1,5, *}$ \\ 1 Unitat de Recerca Biomèdica, Hospital Universitari Sant Joan, Institut d'Investigació Sanitària Pere Virgili, \\ Universitat Rovira i Virgili, 43201 Reus, Spain; marta.riera.borrull@gmail.com (M.R.-B.); \\ ghanabel@gmail.com (A.G.-H.); salvador.fernandezarroyo@gmail.com (S.F.-A.); \\ anna.hernandeza@gmail.com (A.H.-A.); noemi.cabre@gmail.com (N.C.); fedra.luciano@gmail.com (F.L.-M.); \\ jcamps@grupsagessa.com (J.C.) \\ 2 Centro de Investigaciones Biológicas (CIB-CSIC), 28040 Madrid, Spain \\ 3 Molecular Oncology Group, Girona Biomedical Research Insitiute (IDIBGI), 17190 Girona, Spain; \\ ecuyas@idibgi.org (E.C.); jmenendez@idibgi.org (J.A.M.) \\ 4 ProCURE (Program against Cancer Therapeutic Resistance), Metabolism and Cancer Group, \\ Catalan Institute of Oncology, 17190 Girona, Spain \\ 5 The Campus of International Excellence Southern Catalonia, 43003 Tarragona, Spain \\ * Correspondence: jorge.joven@urv.cat; Tel.: +34-977-310-300 (ext. 55409); Fax: +34-977-312-569
}

Received: 12 September 2017; Accepted: 25 October 2017; Published: 28 October 2017

\begin{abstract}
Prevention of the metabolic consequences of a chronic energy-dense/high-fat diet (HFD) represents a public health priority. Metformin is a strong candidate to be incorporated in alternative therapeutic approaches. We used a targeted metabolomic approach to assess changes related to the multi-faceted metabolic disturbances provoked by HFD. We evaluated the protective effects of metformin and explored how pro-inflammatory and metabolic changes respond when mice rendered obese, glucose-intolerant and hyperlipidemic were switched to diet reversal with or without metformin. Mice treated with metformin and diet-reversal showed a dramatically improved protection against HFD-induced hepatic steatosis, a beneficial effect that was accompanied by a lowering of liver-infiltrating pro-inflammatory macrophages and lower release of pro-inflammatory cytokines. Metformin combined with diet reversal promoted effective weight loss along with better glucose control, lowered levels of circulating cholesterol and triglycerides, and reduced adipose tissue content. Our findings underscored the ability of metformin to target the contribution of branched chain amino acids to adipose tissue metabolism while suppressing mitochondrial-dependent biosynthesis in hepatic tissue. The relationship between adipose tissue and liver might provide clinical potential for combining metformin and dietary modifications to protect against the metabolic damage occurring upon excessive dietary fat intake.
\end{abstract}

Keywords: adipose tissue; caloric restriction; energy state; inflammation; liver steatosis; metabolomics

\section{Introduction}

Contemporary high-energy and high-fat diets, coupled with the effect of sedentary lifestyles, are closely related to the convergent epidemics of obesity, insulin resistance, type 2 diabetes (T2D) and non-alcoholic fatty liver disease (NAFLD). These metabolic comorbidities seriously compromise health span and quality of life worldwide [1]. The efficacy of lifestyle modification approaches is low and seriously hampered by relatively unknown cellular metabolic strategies and compensatory pathways induced by reducing fat intake $[2,3]$. 
Severe calorie (energy) restriction (CR) is effective, but it seems impractical outside of research settings. Putative mechanisms are attractive, however, because the adoption of a CR-like lifestyle and the typical diets in industrialized countries operate as extreme ends of the same disease-health metabolic spectrum [4,5]. An alternative strategy, scarcely investigated, might combine lifestyle modification with pharmacotherapy, and in this context efficacy is likely for adenosine monophosphate-activated protein kinase (AMPK) activators [6]. Among available drugs, metformin has been suggested to promote protective effects against metabolic diseases with little or no toxicological significance [7-10]. For example, the combination of metformin and a 70\% restriction in calories yielded superior results compared to either treatment alone in diabetic rats [11]. More recently, metformin alone increased energy expenditure and improved liver damage and development of T2D-like state in HFD-fed C57BL6/J mice [12,13]. In mice, taking metformin results in a shift to microbial species with beneficial effects in energy homeostasis [14]. In humans, similar results are likely, and the clinical usefulness of metformin in combination with modest lifestyle modification could be expanded to patients without diabetes with the goal of differentially affecting other medical outcomes [15-19].

How metformin works is not fully understood, but several lines of evidence suggest a critical role in energy homeostasis via a complex picture that includes the effect of nutrients and molecular crosstalk between metabolic organs, especially the liver, gut and adipose tissue [20,21]. Here, we performed an integrated analysis of the metabolic phenotypes occurring upon feeding mice experimental diets with or without metformin treatment using a targeted metabolic approach. We tested the hypothesis that concomitant metformin and simple diet reversal treatment could ameliorate HFD-induced disturbances.

\section{Results}

\subsection{Effects on the Regulation of Body Weight and Food Intake}

Mice in the HFD group gained weight quicker than chow diet (CD) littermates. Although metformin treatment had no effect on body weight regulation in mice challenged with HFD, it led to a significant reduction in body weight gain in mice on $\mathrm{CD}$ from the fourth week of experiment until the end of the follow-up (24 weeks) (Figure 1A). Body weight gain of HFD-fed mice decreased immediately after switching to CD. Remarkably, administration of metformin was significantly more effective than $C D$ alone in reducing body weight gain, particularly after 6-7 weeks of diet reversal when mice fed $\mathrm{CD}$ alone began to regain lost body weight (Figure 1B).

Despite the gain in weight of HFD mice, the food intake relative to CD-fed-mice was lower. The intake in calories, however, was higher. Data shown in supplementary material indicated differences in energy supply (CD, 3.3 Kcal/g; HFD, $5.7 \mathrm{Kcal} / \mathrm{g}$ ) per gram of consumed food. The source of these calories was also different. Fat was the main provisor in HFD and carbohydrates in CD. Differences in energy expenditure are unlikely in this model. Metformin treatment had no effect on food consumption between groups (Figure 2A,D). 


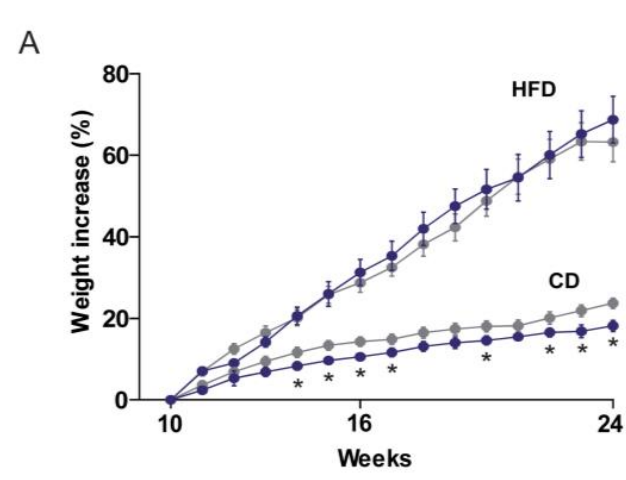

Placebo

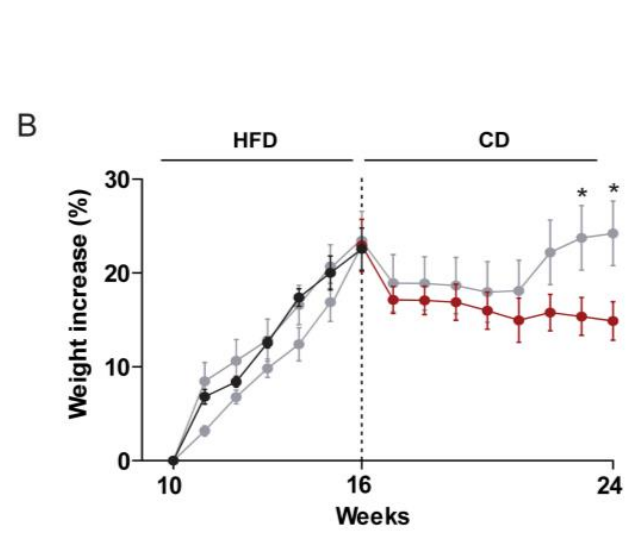

Figure 1. Dietary-induced changes and the effect of metformin on weight control. Overall design in experimental animals. (A) Values obtained in mice upon feeding with experimental diets for 14 weeks. $\mathrm{CD}$, chow diet; HFD, high-fat diet; (B) values obtained after a 6 week period of HFD feeding and shift to $\mathrm{CD}$. Asterisks denote significant $(p<0.05)$ changes compared to the respective group.
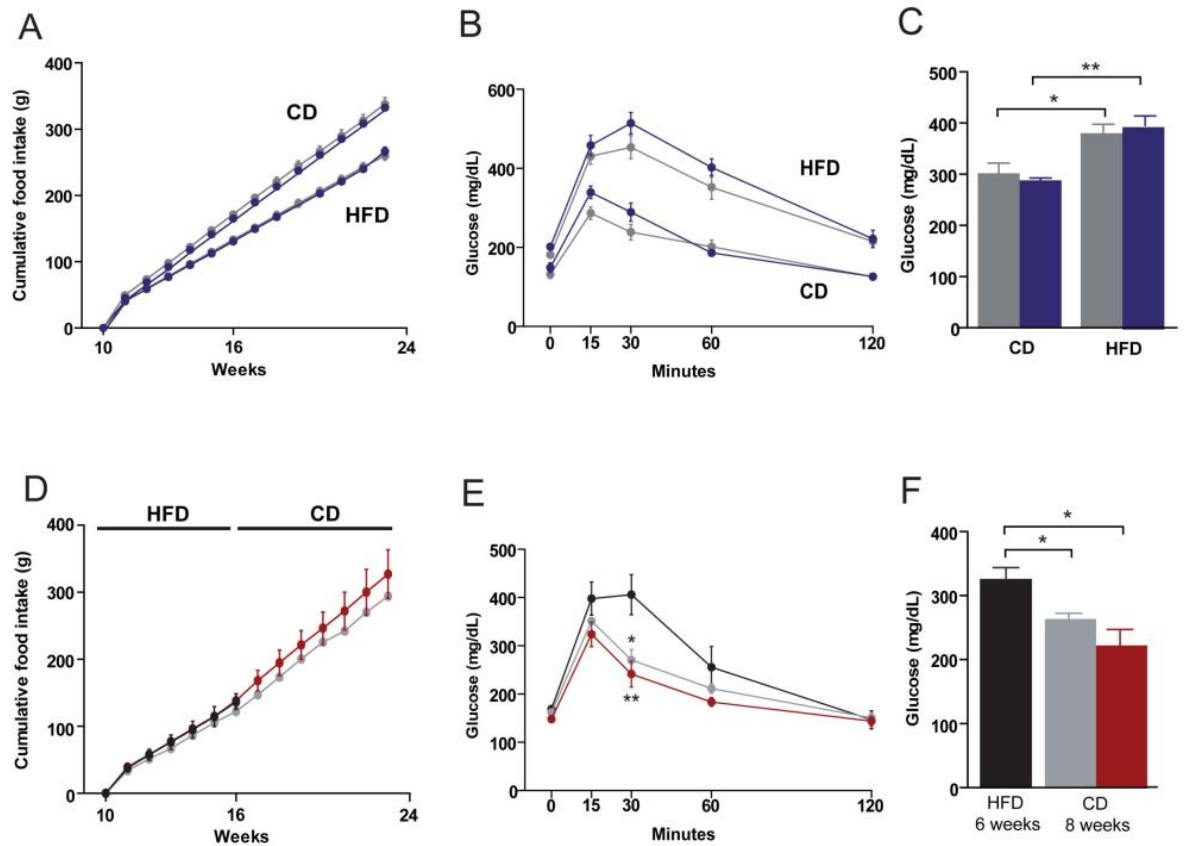

Figure 2. Dietary-induced changes and the effect of metformin on food intake and glucose homeostasis. (A,D) Cumulative food intake, (B,E) glucose tolerance tests, and (C,F) plasma glucose levels segregated by the type of dietary experiment (A-C) CD versus HFD, and (D-F) diet reversal and use of metformin as indicated by the legends. Asterisks denote significant $\left({ }^{*} p<0.05 ;{ }^{* *} p<0.01\right)$ changes. 


\subsection{Effects on Glucose Homeostasis}

Fasting serum glucose levels were significantly higher in the HFD group than in the CD group. To assess the impact of chronic HFD exposure on glucose homeostasis in more detail, both groups were subjected to a glucose tolerance test (GTT). Intraperitoneally injected glucose resulted in a more rapid increase of blood glucose in the HFD group than in the CD group, indicating the development of HFD-induced systemic glucose intolerance. The effect of metformin administration on plasma glucose levels and glucose tolerance was negligible in CD and HFD groups (Figure 2B,C). We then re-evaluated glucose homeostasis in HFD-fed mice subjected to diet reversal with or without metformin treatment (Figure 2E). Diet reversal and metformin were similarly effective in reducing the HFD-provoked increase in plasma glucose (Figure 2F). Of note, although peak values of blood glucose levels were similar for diet reversal alone and with metformin in the GTT, animals treated with metformin exhibited faster glucose clearance (Figure 2E).

\subsection{Effects on Hyperlipidemia}

Plasma levels of cholesterol and triglycerides were significantly higher in the HFD group than in the CD group (Figure 3A). Metformin treatment resulted in a reduction in the concentration of total serum cholesterol and of dense low-density lipoprotein (LDL) cholesterol in CD-fed animals; an effect not observed in HFD-fed animals (Figure 3A,B). Metformin-induced changes to LDL levels in CD-fed mice were accompanied by a significant decrease in serum triglyceride concentrations and of triglycerides in the LDL fraction (Figure 3A,B). Diet reversal to CD abolished the increase in circulating cholesterol promoted by HFD feeding (Figure 3C). Indeed, lipoprotein distribution in mice subjected to diet reversal with or without metformin largely resembled that commonly observed in wild-type animals (i.e., almost all cholesterol in the high-density lipoprotein (HDL) fraction) (Figure 3D). Administration of metformin promoted a further reduction in the circulating levels of cholesterol in diet-switched mice, and also a statistically significant reduction in serum triglyceride concentration (Figure 3C).

A
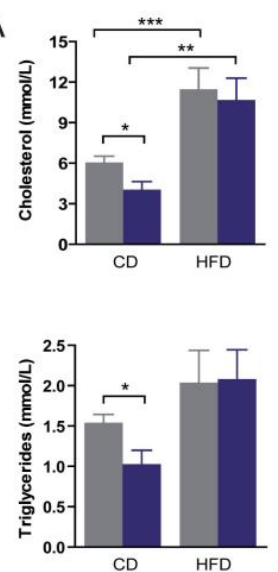

C

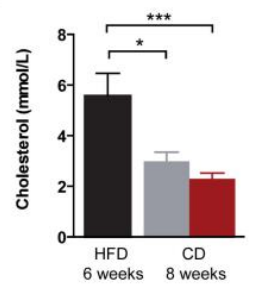

B
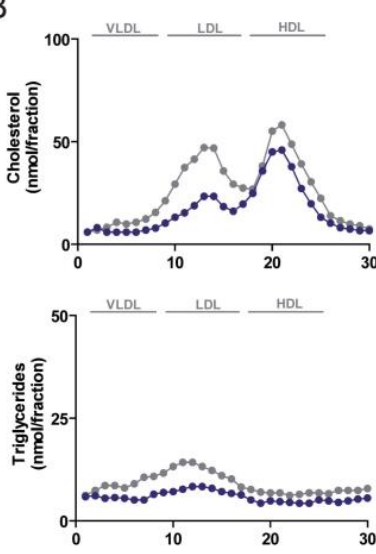

D

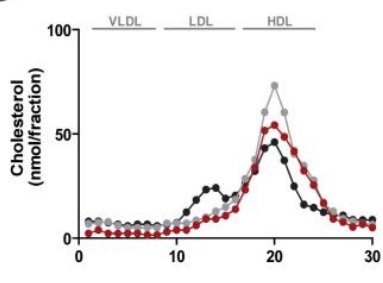

HFD
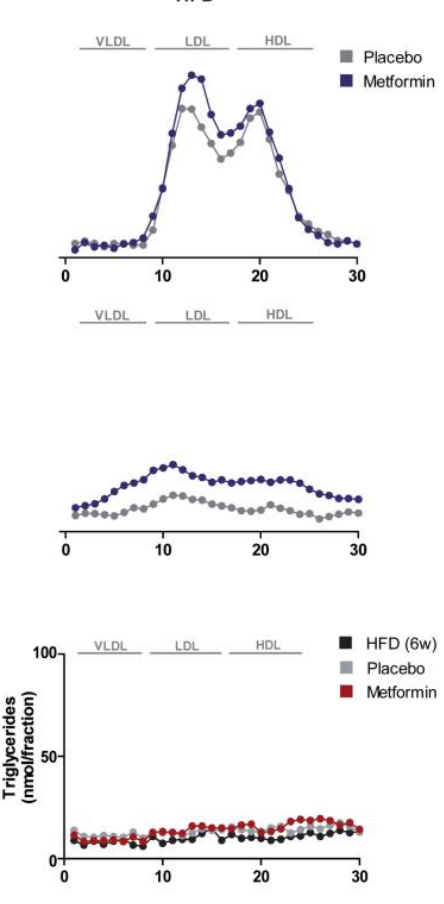

Figure 3. Dietary-induced changes and the effect of metformin on plasma lipids and lipoprotein distribution. (A) Plasma lipids and (B) lipoprotein distribution as measured with fast-performance 
liquid chromatography in mice upon feeding with experimental diets for 14 weeks. CD, chow diet; HFD, high-fat diet; (C,D) same measurements in mice after diet reversal with or without metformin. Asterisks denote significant $\left({ }^{*} p<0.05 ;{ }^{* *} p<0.01 ;{ }^{* * *} p<0.001\right)$ changes as indicated. LDL: low-density lipoprotein; VLDL: very low-density lipoprotein; HDL: high-density lipoprotein.

\subsection{Effects on White Adipose Tissue}

Given the changes in triglyceride levels between CD and HFD groups, we next questioned how metformin might impact epididymal white adipose tissue (eWAT) content. Morphometric analysis of eWAT depots revealed that average adipocyte size in HFD-fed mice was significantly greater than that found in CD-fed mice (Figure 4A,B). Metformin administration significantly decreased adipocyte size and also the relative weight of the eWAT depot in CD-fed mice. By contrast, metformin treatment further increased adipocyte area and also the relative weight of white adipose tissue (WAT) in HFD-fed animals (Figure 4C). Although metformin treatment augmented the loss of the WAT depot in animals subjected to diet reversal and led to a significant decrease in adipocyte area, the average size of adipocytes remained larger than those from animals treated with diet reversal alone (Figure 4D).

A

B
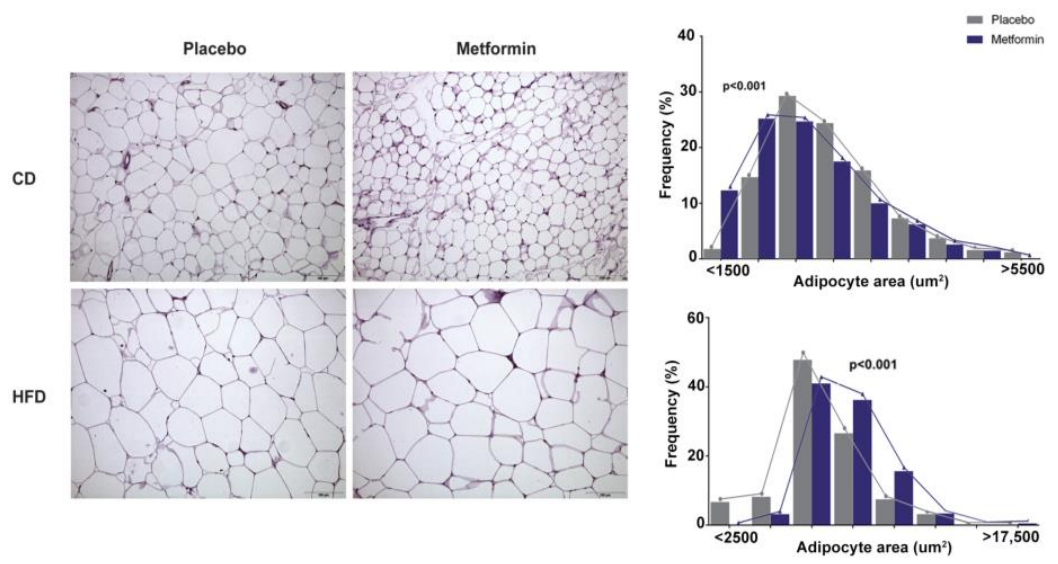

C
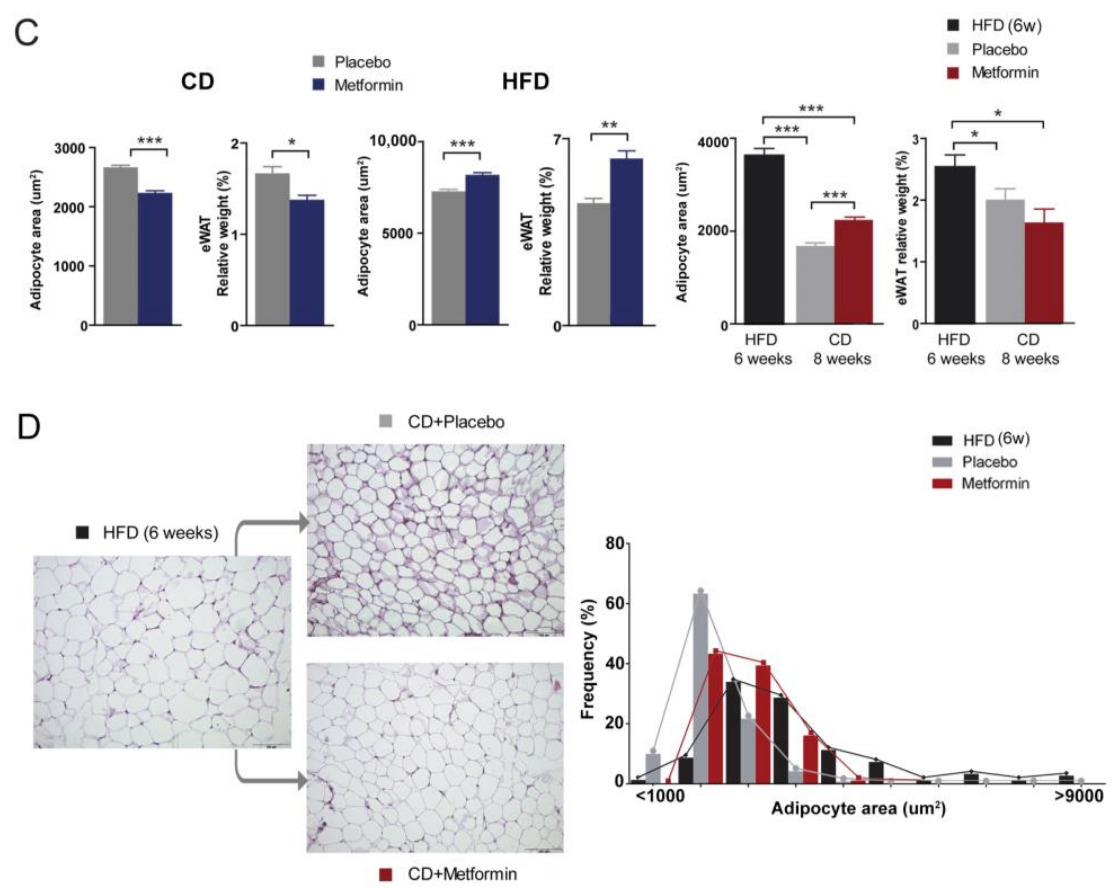

Figure 4. Dietary-induced changes and the effect of metformin on the epididymal WAT phenotype. 
(A) Representative microphotographs $(200 \times)$ showing the differential effects of diet and metformin in epididymal white adipose tissue (eWAT) and (B) frequency distribution of adipocyte size; (C) mean values for adipocyte area and relative weight with respect to body weight in experiments; (C,D) phenotypic changes and frequency distribution of adipocyte size combining shift in diets and metformin. Legends as in Figure 1 and asterisks denote significant $\left({ }^{*} p<0.05 ;{ }^{* *} p<0.01 ;{ }^{* *} p<0.001\right)$ changes as indicated.

\subsection{Effects on Hepatic Steatosis}

Chronic HFD exposure is known to cause lipid accumulation in the liver, a process that ultimately leads to NAFLD and eventually to nonalcoholic steatohepatitis. As expected, HFD-fed animals presented with severe fatty liver disease. No significant differences in hepatic steatosis were found in the $\mathrm{CD}$ and HFD groups following metformin administration (Figure 5A). Remarkably, whereas diet reversal alone failed to ameliorate HFD-induced hepatic steatosis, the combination of diet reversal and metformin treatment significantly reduced the occurrence of steatosis (Figure 5B).

A

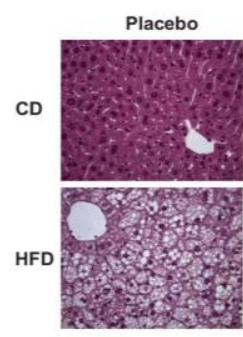

Placebo

C

CD

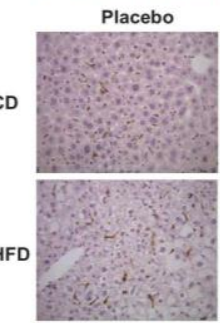

$\mathrm{E}$

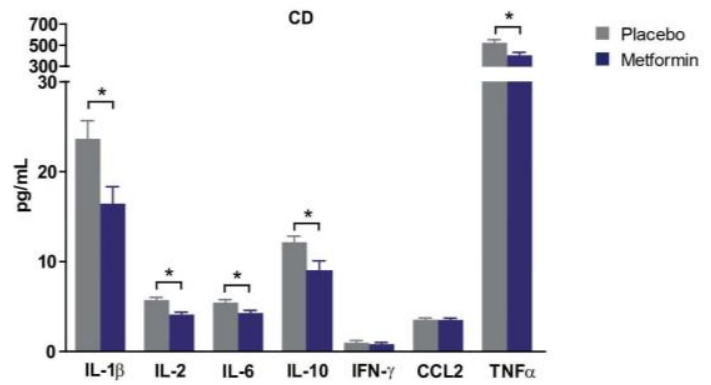

In Placebo

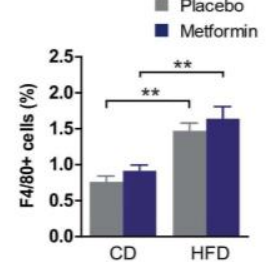

B

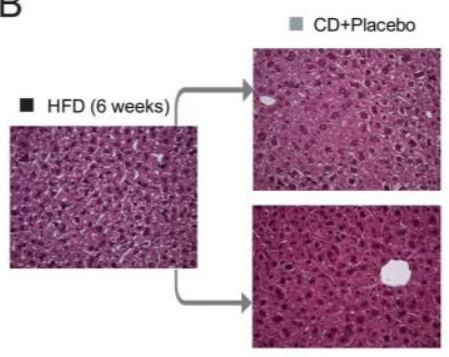

a $\mathrm{CD}+$ Metformin

D

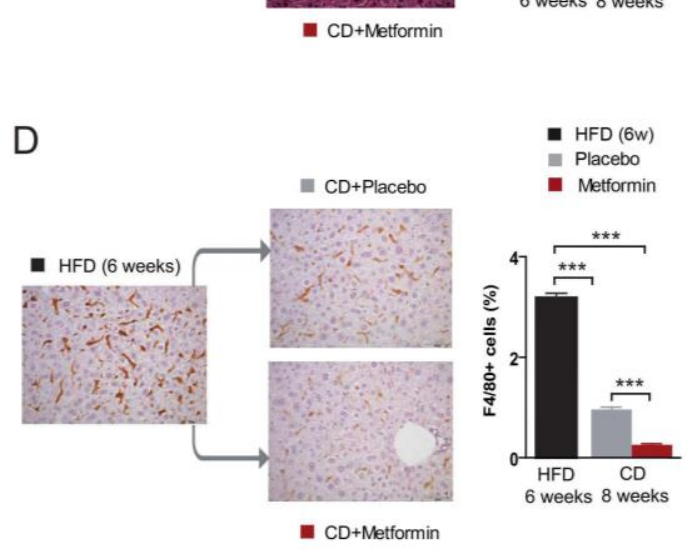

- HFD (6w) - Placebo

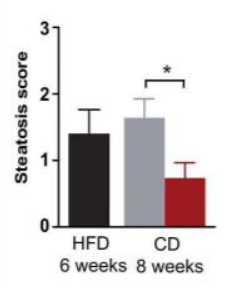

Figure 5. Dietary-induced changes and the effect of metformin on the liver phenotype. Effects of diet and metformin at indicated times during nutritional variations. Representative microphotographs $(100 \times)$ of liver sections stained with H\&E (A,B) and F4/80 immunochemistry (C,D) showing the effects of diet and metformin in steatosis score and proportion of macrophages; (E) the effect of metformin in the hepatic concentration of selected cytokines in CD-fed mice. Legends as in Figure 1 and asterisks denote significant $\left.{ }^{*} p<0.05 ;{ }^{* *} p<0.01{ }^{* * *} p<0.001\right)$ changes as indicated.

\subsection{Effects on Hepatic Inflammation}

There were no signs of ballooning or fibrosis and liver enzymes were not differentially affected by diet, but we detected a significantly increased number of macrophages in liver of 
HFD-fed animals when compared with CD-fed animals, as revealed by immunohistochemistry for F4/80, a pan-marker for murine tissue macrophages (Figure 5C). Diet reversal ameliorated liver inflammation in the HFD group, as demonstrated by the significant decrease in the number of F4/80+ inflammatory cells (Figure 5D). Of note, metformin treatment of diet-reversed animals almost completely eliminated the presence of F4/80+ macrophages (Figure 5D), which also appeared to be enlarged; a morphology that might be suggestive of an activated state following HFD. The ability of metformin to reduce HFD-induced chronic inflammation might involve the reduced production of prototypical pro-inflammatory cytokines including interleukin (IL)- $1 \beta$ and tumor necrosis factor- $\alpha$ $(\mathrm{TNF} \alpha)$, as levels of these cytokines were significantly reduced in metformin-treated mice. Changes were similar in both CD and HFD regimens. For clarity, only values obtained in CD-fed mice with or without metformin are shown in Figure 5E.

\subsection{Effects on the Levels of Energy Metabolites in Hepatic and Adipose Tissue}

The exposure of mice to HFD has an impact on levels of energy metabolites, which is different in WAT and liver. In WAT, HFD led to a decrease in the levels of glycolytic intermediates proximal to glucose-6-phosphate, while increasing the citric acid cycle (CAC) intermediates citrate/isocitrate and $\alpha$-ketoglutarate. Conversely, HFD promoted the accumulation of glycolytic intermediates proximal to glucose-6-phosphate in liver, that is, those intermediates involved in glucose transport and phosphorylation, while significantly decreasing branched-chain amino acids (BCAAs) (Figure 6).

We then evaluated the tissue-specific (WAT versus liver) nature of the impact of metformin for energy metabolites. Metformin treatment led to a significant decrease in the levels of the BCAAs valine, leucine and isoleucine in WAT of mice fed CD, and additionally increased glycolytic intermediates distal to glucose-6-phosphate (phosphoenolpyruvate, pyruvate and lactate) and most of the CAC intermediates (Figure 7A). Although the decrease in the glycolytic intermediates proximal to glucose-6-phosphate remained unaltered by metformin treatment, neither glycolytic intermediates distal to glucose-6-phosphate nor CAC intermediates were significantly altered by metformin in WAT of mice on HFD. Metabolite-based clustering in WAT, obtained by the partial least squares-discriminant analysis (PLS-DA) model, revealed a clear and significant separation between CD and HFD regimens in the absence or presence of metformin treatment in two-dimensional score plots (Figure 7B). When the criteria of variable importance in the projection (VIP scores $\geq 1$ ) in the PLS-DA model were used to maximize the difference of metabolic profiles between the different diet groups, the subset of metabolites majorly impacted were early glycolytic intermediates and BCAAs (Figure 7C). Heatmap visualization, commonly used for unsupervised clustering, revealed a similar segregation of metformin-impacted glycolytic and amino acids metabolites in WAT from CD and HFD groups (Figure 7D). 


\section{Adipose tissue}

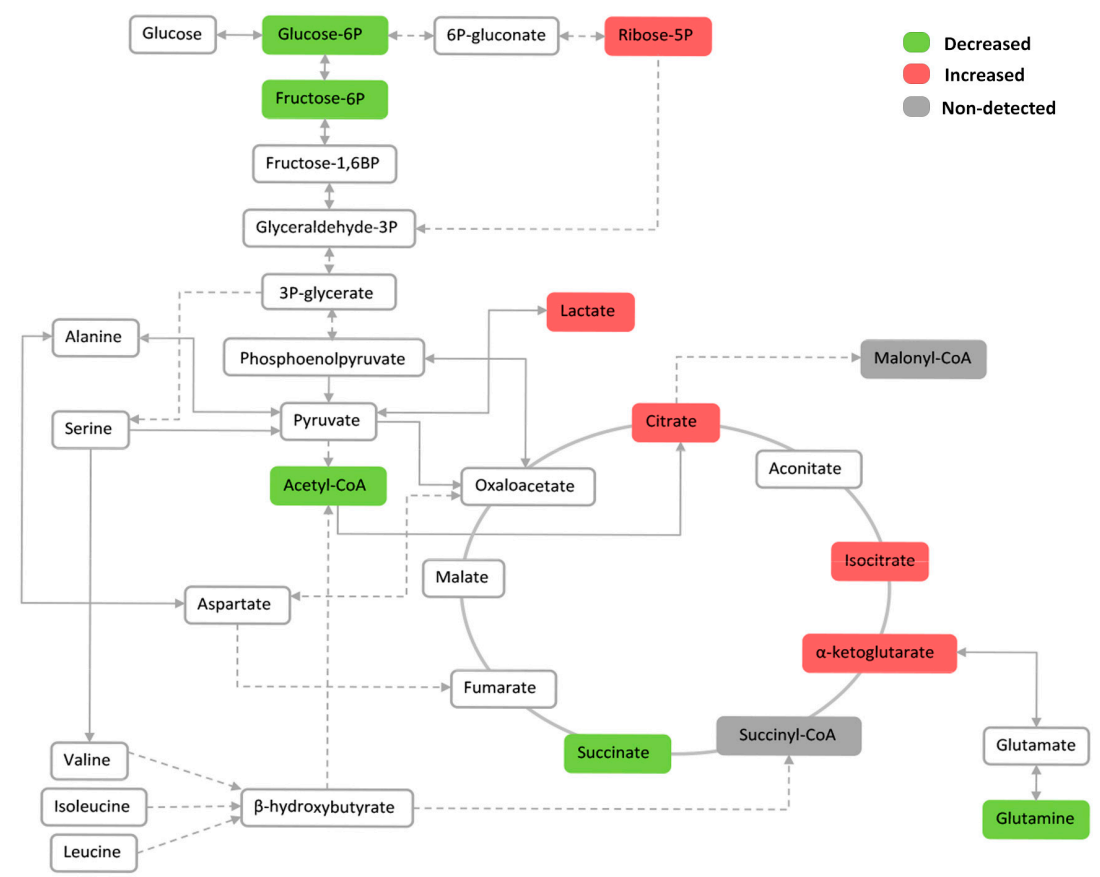

\section{Liver}

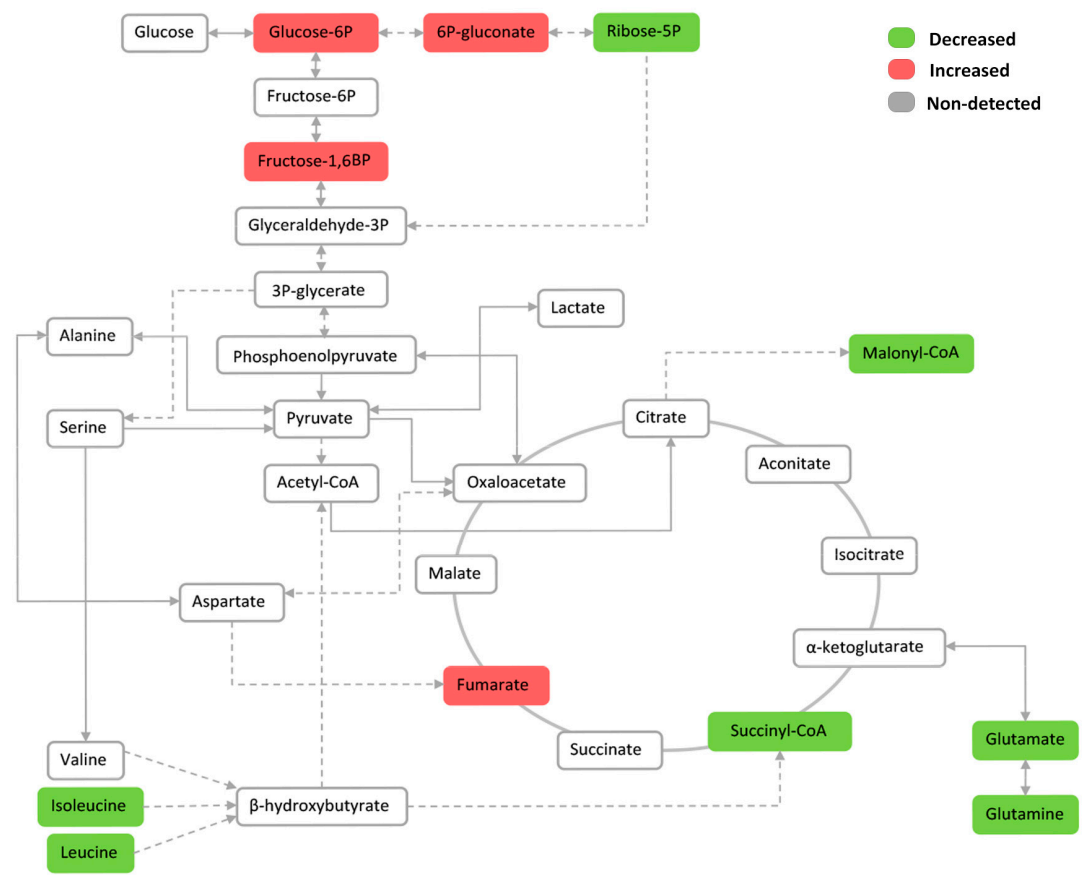

Figure 6. The relative impact of dietary fat on the levels of metabolites associated with energy metabolism in adipose tissue and liver. Metabolites are marked in green, red or grey if they were significantly decreased, increased or non-detected respectively according to the impact of HFD. 
A

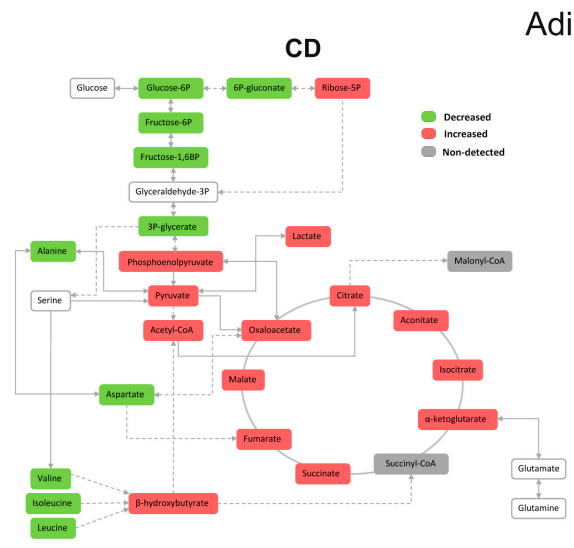

B

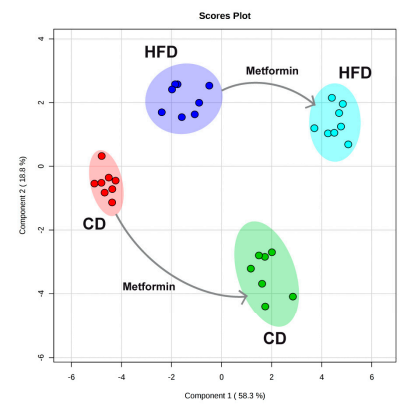

C

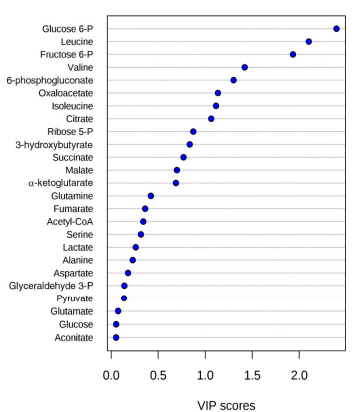

D
Adipose tissue

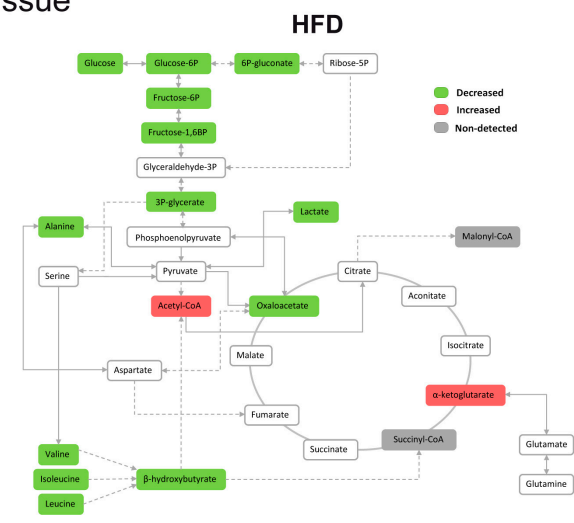

$C D$
$C D+$ metformin
HFD

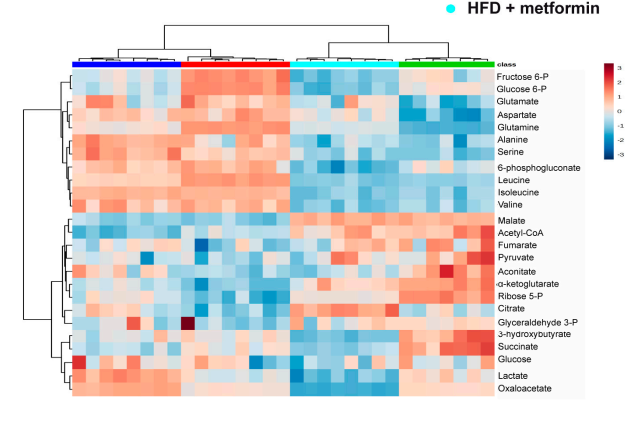

Figure 7. Dietary-induced changes and the effect of metformin on white adipose tissue (WAT) energy metabolites. (A) The effect of both diets is segregated to highlight specific changes in metformin response; metabolites are marked in green, red or grey if they were significantly decreased, increased or non-detected respectively; (B) partial least square discriminant analysis indicates visually the role of the measured metabolites in discriminating among the different experimental groups; (C) random forests were used to rank the importance of metabolites without supervision, in order to explain the differential effect of metformin; (D) standardized metabolite concentrations represented as a heatmap. Mice populations with different diets and metformin treatment are reported as a color code in the upper part of the graph, while metabolite names have been assigned to rows.

A completely different picture emerged when assessing metformin-driven metabolomic shifts in liver from CD and HFD groups. The significant reduction of phosphoenolpyruvate and acetyl-CoA, accompanied by an increase in the levels of glycolytic intermediates proximal to glucose-6-phosphate, including glucose-6-phosphate itself, 6-phosphogluconate and fructose 1,6-bisphosphate, suggested a reduced entry of glucose carbon into mitochondrial biosynthetic metabolism in mice fed $C D$ together with metformin treatment (Figure 8A). Mitochondria from livers of mice fed HFD apparently exhibited an increased dependency in reductive glutamine metabolism capable of replenishing the high levels of lipogenic acetyl-CoA/malonyl-CoA as an adaptive response to metformin (Figure 8A). Metabolite-based clustering in liver obtained by the PLS-DA model confirmed a clear and significant separation of animals fed a CD alone and with metformin (Figure 8B). Conversely, a small overlap occurred in animals fed HFD alone and with metformin (Figure 8B). When the distinct metabolites between hepatic groups were selected with the criteria of VIP $\geq 1$ in the PLS-DA model, the subset of metabolites majorly impacted were glycolytic intermediates and those metabolites related to the biosynthetic fates of glutamine metabolism (Figure 8C). Unlike the scenario observed with the similar impact of metformin for WAT metabolites in CD- and HFD-fed mice, the segregation of the selected metabolites obtained by using heatmap visualization confirmed a completely distinct segregation of metformin-impacted metabolites in liver of CD- and HFD-fed mice (Figure 8D). 
A

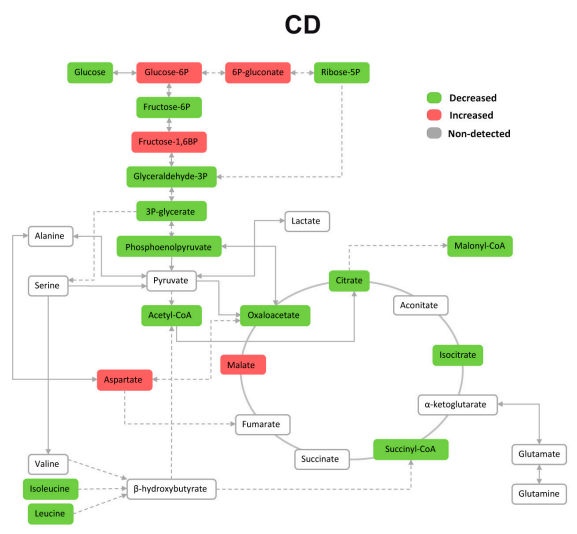

B

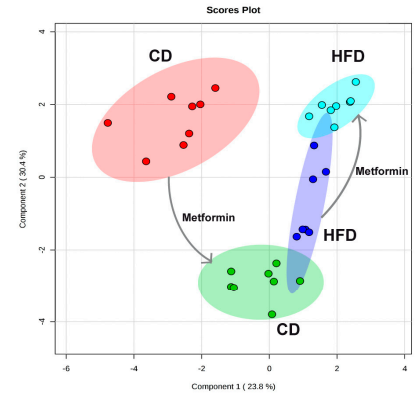

C

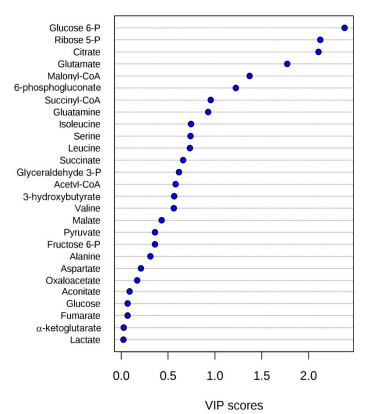

D
Liver
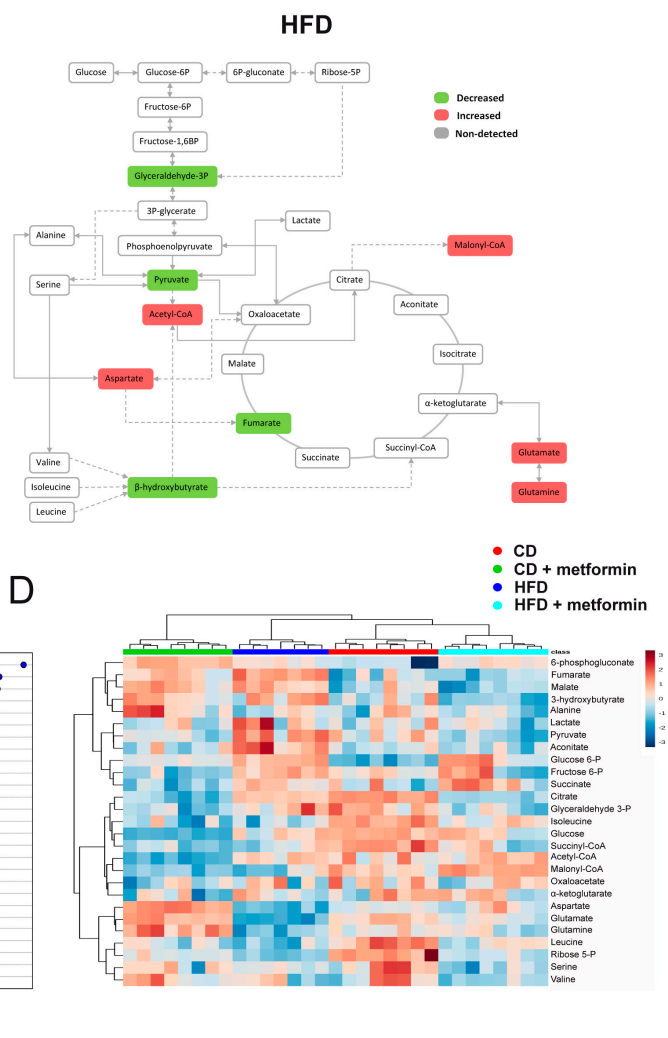

Figure 8. Dietary-induced changes and the effect of metformin on hepatic energy metabolites. Descriptive details are conserved as in Figure 7.

\section{Discussion}

Metformin treatment might play a major role in preventing the metabolic disturbances caused by exposure to HFD in both adipose and liver tissues, and might enlarge the benefits of simple dietary restrain. Feeding mice with HFD promoted the appearance of classical metabolic derangements occurring after excessive intake of dietary lipids. When HFD-fed animals were subjected to diet reversal alone, and also to metformin for a short duration, it became apparent that switching to regular feeding alone could not fully reverse the metabolic abnormalities provoked by the initial exposure to HFD. However, the addition of metformin treatment to diet reversal ameliorated the metabolic status associated with the previous HFD pattern. Animals started to regain body weight six weeks after switching to normal diet, but the trend towards lower weight gain remained unaltered in the presence of metformin, likely indicating that the effect of metformin in weight loss maintenance could prevent the long-term consequences of HFD-associated overweight. The combination between HFD and metformin did not improve glucose tolerance. Our results suggest mechanisms related to insulin signaling. Future research should take into consideration the combined effects of both insulin and metformin [22,23]. Metformin also decreased the circulating levels of cholesterol and triglycerides, revealing its capacity to protect from the long-term effects of HFD-imposed periods of metabolic hyperlipidemia [24].

Exposure to HFD causes chronic inflammation in the liver, a critical factor for the development of obesity-related glucose intolerance, insulin resistance and NAFLD progression [25]. This key mechanistic component of the lifelong risk for developing metabolic complications in response to energy overload is affected by metformin. Mice treated with metformin and diet-reversal exhibited an improved protection against HFD-induced hepatic steatosis, which was accompanied by a significant lowering of liver-infiltrating pro-inflammatory macrophages as well as lower levels of 
major pro-inflammatory cytokines. The ability of metformin to modulate the polarization or migration of these cells has been recently demonstrated in tumor-associated macrophages [26]. Future studies should examine whether metformin contributes to the reduction of hepatic and adipose tissue inflammation by preventing either the recruitment or pro-inflammatory activation of macrophages (or both) [27].

Diet reversal failed to restore HFD-induced hepatic damage unless combined with metformin. Metformin decreased the flow of glucose- and glutamine-derived CAC intermediates and appears to overcome the hepatic ability to store and metabolize carbohydrates, thereby better preventing HFD-induced hepatic damage when switching to normal diet occurs. Mechanisms remain to be fully understood, but are possibly related to known effects on mitochondrial-dependent biosynthetic activity and de novo lipogenesis $[28,29]$. Hence, elevated mitochondrial CAC function and increased flow through anabolic pathways play crucial roles in the pathobiology of fatty liver and insulin resistance induced by an obesogenic diet $[30,31]$. This study does not provide clear evidence on how metformin and diet reversal may share mechanisms, but suggests that metformin might alleviate inflammation and that mitochondrial adaptations might be explored as mechanisms of HFD-induced hepatic complications.

It appears that adipocyte hypertrophy, a hallmark of WAT enlargement in obesity, is corrected upon diet reversal. The frequency distribution of adipocyte areas across the WAT depot suggests an apparently limited capacity of metformin to remodel WAT tissue architecture, likely indicating a specific protection from hepatic insulin resistance rather than a protection from systemic insulin resistance. This effect of metformin is diet-specific and likely represents a defense mechanism to protect the liver [32]. Recent data suggest that impaired adipogenesis is associated with insulin resistance [23]. The combined administration of metformin and insulin might provide mechanistic clues to support the synergic effect of metformin and dietary restraint. Future research should include the effect of metformin converging in mechanisms involving BCAAs. We now know $[33,34]$ that differentiated adipocytes exhibit an increased catabolic flux of BCAAs, such as leucine and isoleucine, that account for a significant amount of lipogenic acetyl-CoA pools. In this regard, the capacity of metformin to target the contribution of BCAAs to WAT metabolism is noteworthy. By altering the functional integrity of this tissue, the up-regulation of the BCAA degradation pathway might contribute to the beneficial effects elicited by metformin beyond those of diet reversal alone. The increased degradation of BCAAs may help in maintaining energy homeostasis and glucose homeostasis providing substrates for the tricarboxylic acid cycle. The increased use of BCAA may also indicate an increased protein synthesis.

Although there is still controversy about the mechanisms of action of metformin [35], their health-promoting effects are largely viewed as the consequence of its ability to simultaneously target the core nutrient-sensing networks insulin/IGF-1, at the non-cell autonomous level, and AMPK/mTOR, at the cell-autonomous level [7,36-38]. Alternatively, we do not discard primary downstream consequences on a single master mechanism that has not yet been identified. We have found robust patterns indicating the potential of metformin to serve as a model compound for preventing HFD-driven progression of metabolic complications. The clinical combination of metformin-based pharmacotherapy with dietary modification might herald the development of much-needed therapeutic and preventive strategies against metabolic consequences of excessive dietary fat intake.

\section{Materials and Methods}

\subsection{Animals, Animal Care and Dietary Details}

Low-density lipoprotein receptor-deficient mice $\left(\mathrm{Ldlr}^{-/-}\right)$were used. We have previously shown that this is a robust model to assess the effect of nutrition in a context of subclinical chronic inflammation, which reproducibly measure objective and quantifiable metabolic characteristics resembling metabolic syndrome and includes hyperlipidemia without the confounding effects 
of diabetes $[39,40]$. Male $\mathrm{Ldlr}^{-/-}$mice in a C57BL/6 genetic background were obtained by breeding animals purchased from Jackson Laboratory (Bar Harbor, ME, USA) and maintained under controlled temperature $\left(22^{\circ} \mathrm{C}\right)$, humidity $(50 \%)$ and lighting $(12 \mathrm{~h}-12 \mathrm{~h}$ light-dark cycle). To prevent sex-dependent variability, female animals were not included [39]. All procedures were performed by dedicated staff in accordance with current regulations and supervision by the Ethics Committee on Animal Experimentation of the Universitat Rovira i Virgili (protocol GC-URV-0235-03.18.2014) following European guidelines (Directive 2010/63/EU). Mice had ad libitum access to water and control breeder chow diet (CD, calories $(3.3 \mathrm{Kcal} / \mathrm{g}$ ) were from protein $(19 \%)$, fat (roughly $9 \%$ ) and carbohydrates (72\%)) prepared by Scientific Animal Food \& Engineering, Augy, France, until 10 weeks of age and throughout the experiments. The effects of $C D$ were compared to those obtained with a high-fat diet (HFD) prepared by Ssniff Spezialdiäten (Soest, Germany), in which calories $(5.7 \mathrm{Kcal} / \mathrm{g}$ ) were from protein (19\%), fat (roughly 60\%) and carbohydrates (21\%). Additional information on supplied nutrients may be found in Supplementary Table S1.

\subsection{Experimental Design and Metformin Provision}

The animals were allocated to experimental groups using computer-generated randomization schedules, and the investigators responsible for the assessment of outcomes had no knowledge of the experimental group to which the animals belonged. No animals were excluded from the analysis. We first explored the metformin response in mice fed with either the original CD or HFD for 14 weeks. Mice were allocated into two dietary groups $(n=16$, each) and further divided in mice receiving metformin (Sigma, Madrid, Spain) or placebo (Monteloeder, Elche, Spain) daily ( $n=8$, each). Mice were sacrificed at 24 weeks using isoflurane inhalation. We proceeded similarly in parallel experiments to examine the metformin response in mice with adverse inflammatory and metabolic status established through feeding animals with HFD for 6 weeks. For comparative analysis, some animals $(n=6)$ were sacrificed at this time and other littermates were then fed with HFD or CD for other 8 weeks. Those mice fed with $\mathrm{CD}$ were divided to receive metformin or placebo $(n=8$, each) to assess whether metformin potentiates the effects of switching to CD. Mice were sacrificed at 24 weeks after a similar fasting time ( $4 \mathrm{~h}$ with a maximum difference of $15 \mathrm{~min}$ ).

We used metformin dissolved in drinking water $\left(5 \mathrm{mg} \cdot \mathrm{mL}^{-1}\right)$ to provide $250 \mathrm{mg} \cdot \mathrm{kg}^{-1} \cdot \mathrm{day}^{-1}$. As previously described, mean plasma concentrations in mice were similar to that obtained in humans with a dose of $1.25 \mathrm{~g} \cdot$ day $^{-1}$ [36]. Metformin did not accumulate in plasma after continued administration. The choice of this route of administration was based in previously published data $[32,41]$. In our hands, the action of metformin might be dose- and time-dependent, because unbalanced plasma concentrations of metformin were observed when metformin was given by either bolus gavage or intra-peritoneal injection. We did not achieve sufficient reproducibility when adding metformin to the diets during the manufacturing process and the drug was mostly but irregularly consumed during the night.

\subsection{Sample Collection, Analytical Methods and Histological Analysis}

Glucose tolerance tests (GTT) were performed in all animals one week before their sacrifice by injecting intraperitoneally glucose in saline solution $\left(2 \mathrm{mg} \cdot \mathrm{g}^{-1}\right.$ of body weight $)$ after $4 \mathrm{~h}$ of fasting. Blood was drawn from the tail to measure glucose levels (Roche Diagnostics, Basel, Switzerland), 0, 15, 30, 60 and $120 \mathrm{~min}$ after the injection. Blood samples were also collected from anesthetized animals into EDTA-treated blood collection tubes during sacrifice and immediately centrifuged and stored at $-80{ }^{\circ} \mathrm{C}$ until analysis. There were no detectable iatrogenic experimental variables. Plasma concentrations of glucose, cholesterol, triglycerides and liver enzymes were measured by standard assays in an automated analyzer Synchron LXi 725 (Beckman Coulter, IZASA, Barcelona, Spain). Plasma lipoproteins were separated by fast-performance liquid chromatography (FPLC) using a Bio-Rad Bio Logic Duo Flow 10 system (Bio-Rad, Alcobendas, Spain). Serum pooled samples from each group $(200 \mu \mathrm{L})$ were injected into a Superose 6/300 GL column (GE Healthcare Europe GmbH, 
Munich, Germany), and $500 \mu \mathrm{L}$ fractions were collected. Cholesterol and triglycerides concentrations were analyzed in each fraction as reported [39]. Organs were perfused in phosphate buffered saline. Fractions of the liver were homogenized using a Precellys 24 homogenizer (Bertin Technologies, Toulouse, France) in lysis buffer containing protease inhibitors at a concentration of $250 \mu \mathrm{g} / \mathrm{mL}$. The levels of interleukin (IL)-1 $\beta$, IL-2, IL-6, IL-10, interferon- $\gamma$, chemokine (C-C motif) ligand 2 (CCL2), and tumor necrosis factor- $\alpha$ (TNF $\alpha$ ) were measured in the homogenates following the manufacturer's instructions using Bio-plexProTM magnetic bead-based assays (Bio-Rad, Madrid, Spain) on the Luminex platform (Bio-Rad). Other removed tissue samples such as liver or epididimal white adipose tissue were removed, weighed and stored at $80{ }^{\circ} \mathrm{C}$ until needed. For histological examination, tissue samples were fixed for $24 \mathrm{~h}$ in 10\% neutral-buffered formalin, paraffin-embedded and stained with hematoxylin and eosin (H\&E). The hepatic macrophages (anti F4/80, Serotec, Oxford, UK) were examined by immunohistochemistry. The extent of steatosis in the liver, the proportion of F4/80 stained cells and the adipocyte size of epididymal white adipose tissue (eWAT) were estimated by image analysis software (AnalySIS, Soft Imaging System, Munster, Germany) essentially as described [42,43].

\subsection{Targeted Metabolomics}

The list of metabolites of major pathways related to energy metabolism was designed with the rationale that cells must allocate nutrients toward boosting glycolysis, and to generate adenosine triphosphate (ATP) and intermediates for macromolecule biosynthesis. Metabolites were quantitatively measured as described [40]. Briefly, metabolites in liver $(50 \mathrm{mg})$ and epididymal white adipose tissue (eWAT; $100 \mathrm{mg}$ ) were extracted in $1 \mathrm{~mL}$ of methanol/water (8:2) using a Precellys 24 system (Izasa, Barcelona, Spain). After centrifugation at 14,000 rpm $10 \mathrm{~min}$ at $4{ }^{\circ} \mathrm{C}$, supernatants were collected and the homogenization step repeated. Nonpolar compounds were further extracted in chloroform/methanol (2:1). All supernatants were centrifuged, filtered using $0.22 \mu \mathrm{m}$ filters, and freeze-dried overnight. Samples were dried under $\mathrm{N}_{2}$, derivatized using methoxyamine dissolved in pyridine $(40 \mathrm{mg} / \mathrm{mL}$ ) and $\mathrm{N}$-methyl- $\mathrm{N}$-(trimethylsilyl)-trifluoroacetamide and injected into a 7890A gas chromatograph coupled with an electron impact source to a 7200 quadrupole time-of-flight mass spectrometer (MS) equipped with a 7693 auto-sampler module and a J\&W Scientific HP-5MS column $(30 \mathrm{~m} \times 0.25 \mathrm{~mm}, 0.25 \mu \mathrm{m})$ (Agilent Technologies, Santa Clara, CA, USA). We measured 31 metabolites in related pathways, including the pentose-phosphate, glycolysis and gluconeogenesis, citric acid cycle (CAC) and metabolism of amino acids (see Figures 6-8). Values in eWAT homogenates were lower than in liver. In particular, malonyl-CoA and succinyl-CoA in eWAT were not considered because, although detected, they were under the limit of quantification using these conditions.

\subsection{Statistical Analysis}

All results are shown as the mean \pm SD unless otherwise stated. Differences between groups were assessed with the Mann-Withney $U$ test (nonparametric) and considered statistically significant when $p<0.05$. Some comparisons required one-way ANOVA. All statistical analyses were carried out using the GraphPad Prism 6.0 Software, Inc. (La Jolla, CA, USA). For the metabolomic analysis, the obtained raw data were processed and compounds were detected and quantified using the Qualitative and Quantitative Analysis B.06.00 software (Agilent Technologies). Results were compared by one-way ANOVA with Dunnett's multiple pair-wise comparison tests using a significance threshold of 0.05 . MetaboAnalyst 3.0, available on the web (Available online: http:/ /www.metaboanalyst.ca/) was used to generate meaningful scores/loading plots [44].

\section{Conclusions}

A metformin-induced response may assist in the prevention of the metabolic consequences of obesogenic diets and potentiate the benefits of dietary restraint. Metformin effects are most notably observed in the development and progression of NAFLD. In adipose tissue, metformin targets the contribution of BCAAs, most likely by up-regulating their degradation. Future research should 
include elucidating the mechanisms by which metformin mediates global epigenetic programming in metabolic tissues, ascertaining the effect of activating AMPK in skeletal muscle and to assessing the likely additive effects with fasting-mimicking diets.

Supplementary Materials: Supplementary materials can be found at www.mdpi.com/1422-0067/18/11/2263/s1.

Acknowledgments: Current work in our laboratories is supported by grants from the Plan Nacional de I+D+I, Spain, Instituto de Salud Carlos III (Grant PI15/00285 co-founded by the European Regional Development Fund (FEDER)) to Jorge Joven, and the Ministerio de Ciencia e Innovación (Grant SAF2012-38914) to Javier Menendez. We also acknowledge the support by the Agència de Gestió d'Ajuts Universitaris i de Recerca (AGAUR) (Grants 2014 SGR1227 and 2014 SGR229), and the Fundació La Marató de TV3. The funders had no role in study design, data collection and analysis, decision to publish, or preparation of the manuscript.

Author Contributions: Jorge Joven and Javier A. Menendez conceived and designed the study. Marta Riera-Borrull, Anabel García-Heredia, Salvador Fernández-Arroyo, Anna Hernández-Aguilera and Noemí Cabré performed experiments and molecular assays. Anabel García-Heredia, Elisabet Cuyàs and Fedra Luciano-Mateo performed immunohistochemical assays. Marta Riera-Borrull and Salvador Fernández-Arroyo performed metabolomics assays. Jordi Camps and Javier A. Menendez contributed important reagents. Marta Riera-Borrull, Jordi Camps and Jorge Joven performed data interpretation. Jordi Camps, Javier A. Menendez and Jorge Joven prepared the manuscript, which was revised and finally approved by all authors.

Conflicts of Interest: The authors declare no conflict of interest.

\section{References}

1. Hernández-Aguilera, A.; Fernández-Arroyo, S.; Cuyàs, E.; Luciano-Mateo, F.; Cabre, N.; Camps, J.; Lopez-Miranda, J.; Menendez, J.A.; Joven, J. Epigenetics and nutrition-related epidemics of metabolic diseases: Current perspectives and challenges. Food Chem. Toxicol. 2016, 96, 191-204. [CrossRef] [PubMed]

2. Hardie, D.G.; Schaffer, B.E.; Brunet, A. AMPK: An Energy-Sensing Pathway with Multiple Inputs and Outputs. Trends Cell Biol. 2016, 26, 190-201. [CrossRef] [PubMed]

3. Massucci, F.A.; Wheeler, J.; Beltrán-Debón, R.; Joven, J.; Sales-Pardo, M.; Guimerà, R. Inferring propagation paths for sparsely observed perturbations on complex networks. Sci. Adv. 2016, 2, e1501638. [CrossRef] [PubMed]

4. Mattison, J.A.; Roth, G.S.; Beasley, T.M.; Tilmont, E.M.; Handy, A.M.; Herbert, R.L.; Longo, D.L.; Allison, D.B.; Young, J.E.; et al. Impact of caloric restriction on health and survival in rhesus monkeys from the NIA study. Nature 2012, 489, 318-321. [CrossRef] [PubMed]

5. Roth, G.S.; Ingram, D.K. Manipulation of health span and function by dietary caloric restriction mimetics. Ann. N. Y. Acad. Sci. 2016, 1363, 5-10. [CrossRef] [PubMed]

6. Smith, B.K.; Marcinko, K.; Desjardins, E.M.; Lally, J.S.; Ford, R.J;; Steinberg, G.R. Treatment of nonalcoholic fatty liver disease: Role of AMPK. Am. J. Physiol. Endocrinol. Metab. 2016, 311, E730-E740. [CrossRef] [PubMed]

7. Barzilai, N.; Crandall, J.P.; Kritchevsky, S.B.; Espeland, M.A. Metformin as a Tool to Target Aging. Cell Metab. 2016, 23, 1060-1065. [CrossRef] [PubMed]

8. Menendez, J.A.; Joven, J. One-carbon metabolism: An aging-cancer crossroad for the gerosuppressant metformin. Aging 2012, 4, 894-898. [CrossRef] [PubMed]

9. Corominas-Faja, B.; Quirantes-Piné, R.; Oliveras-Ferraros, C.; Vazquez-Martin, A.; Cufí, S.; Martin-Castillo, B.; Micol, V.; Joven, J.; Segura-Carretero, A.; Menendez, J.A. Metabolomic fingerprint reveals that metformin impairs one-carbon metabolism in a manner similar to the antifolate class of chemotherapy drugs. Aging 2012, 4, 480-498. [CrossRef] [PubMed]

10. Viollet, B.; Guigas, B.; Sanz Garcia, N.; Leclerc, J.; Foretz, M.; Andreelli, F. Cellular and molecular mechanisms of metformin: An overview. Clin. Sci. 2012, 122, 253-270. [CrossRef] [PubMed]

11. Linden, M.A.; Lopez, K.T.; Fletcher, J.A.; Morris, E.M.; Meers, G.M.; Siddique, S.; Laughlin, M.H.; Sowers, J.R.; Thyfault, J.P.; Ibdah, J.A.; et al. Combining metformin therapy with caloric restriction for the management of type 2 diabetes and nonalcoholic fatty liver disease in obese rats. Appl. Physiol. Nutr. Metab. 2015, 40, 1038-1047. [PubMed] 
12. Schommers, P.; Thurau, A.; Bultmann-Mellin, I.; Guschlbauer, M.; Klatt, A.R.; Rozman, J.; Klingenspor, M.; de Angelis, M.H.; Alber, J.; Gründemann, D.; et al. Metformin causes a futile intestinal-hepatic cycle which increases energy expenditure and slows down development of a type 2 diabetes-like state. Mol. Metab. 2017, 6, 737-747. [CrossRef] [PubMed]

13. Woo, S.L.; Xu, H.; Li, H.; Zhao, Y.; Hu, X.; Zhao, J.; Guo, X.; Guo, T.; Botchlett, R.; Qi, T.; et al. Metformin ameliorates hepatic steatosis and inflammation without altering adipose phenotype in diet-induced obesity. PLoS ONE 2014, 9, e91111. [CrossRef] [PubMed]

14. De Vadder, F.; Kovatcheva-Datchary, P.; Goncalves, D.; Vinera, J.; Zitoun, C.; Duchampt, A.; Bäckhed, F.; Mithieux, G. Microbiota-generated metabolites promote metabolic benefits via gut-brain neural circuits. Cell 2014, 156, 84-96. [CrossRef] [PubMed]

15. Brunkwall, L.; Orho-Melander, M. The gut microbiome as a target for prevention and treatment of hyperglycaemia in type 2 diabetes: From current human evidence to future possibilities. Diabetologia 2017, 60, 943-951. [CrossRef] [PubMed]

16. Foretz, M.; Viollet, B. Metformin takes a new route to clinical efficacy. Nat. Rev. Endocrinol. 2015, 11, 390-392. [CrossRef] [PubMed]

17. Pernicova, I.; Korbonits, M. Metformin-Mode of action and clinical implications for diabetes and cancer. Nat. Rev. Endocrinol. 2014, 10, 143-156. [CrossRef] [PubMed]

18. Saisho, Y. Metformin and Inflammation: Its Potential Beyond Glucose-lowering Effect. Endocr. Metab. Immune Disord. Drug Targets 2015, 15, 196-205. [CrossRef] [PubMed]

19. Domecq, J.P.; Prutsky, G.; Leppin, A.; Sonbol, M.B.; Altayar, O.; Undavalli, C.; Wang, Z.; Elraiyah, T.; Brito, J.P.; Mauck, K.F.; et al. Clinical review: Drugs commonly associated with weight change: A systematic review and meta-analysis. J. Clin. Endocrinol. Metab. 2015, 100, 363-370. [CrossRef] [PubMed]

20. Rena, G.; Hardie, D.G.; Pearson, E.R. The mechanisms of action of metformin. Diabetologia 2017. [CrossRef] [PubMed]

21. Luciano-Mateo, F.; Hernández-Aguilera, A.; Cabre, N.; Camps, J.; Fernández-Arroyo, S.; Lopez-Miranda, J.; Menendez, J.A.; Joven, J. Nutrients in Energy and One-Carbon Metabolism: Learning from Metformin Users. Nutrients 2017, 9, 121. [CrossRef] [PubMed]

22. Zhou, Z.; Ren, L.; Zhan, P.; Yang, H.; Chai, D.; Yu, Z. Metformin exerts glucose-lowering action in high-fat fed mice via attenuating endotoxemia and enhancing insulin signaling. Acta Pharmacol. Sin. 2016, 43, 1063-1075. [CrossRef] [PubMed]

23. Jaganjac, M.; Aluraikhy, S.; Al-Khelaifi, F.; Al-Jaber, M.; Bashah, M.; Mazloum, N.A.; Zarkovic, K.; Zarkovic, N.; Waeg, G.; Kafienah, W.; et al. Combined metformin and insulin treatment reverses metabolically impaired omental adipogenensis and accumulation of 4-hydroxynonenal in obese diabetic patients. Redox Biol. 2017, 12, 483-490. [CrossRef] [PubMed]

24. Menendez, J.A.; Martin-Castillo, B.; Joven, J. Metformin and cancer: Quo vadis et cui bono? Oncotarget 2016, 7, 54096-54101. [CrossRef] [PubMed]

25. Ota, T.; Takamura, T.; Kurita, S.; Matsuzawa, N.; Kita, Y.; Uno, M.; Akahori, H.; Misu, H.; Sakurai, M.; Zen, Y.; et al. Insulin resistance accelerates a dietary rat model of nonalcoholic steatohepatitis. Gastroenterology 2007, 132, 282-293. [CrossRef] [PubMed]

26. Ding, L.; Liang, G.; Yao, Z.; Zhang, J.; Liu, R.; Chen, H.; Zhou, Y.; Wu, H.; Yang, B.; He, Q. Metformin prevents cancer metastasis by inhibiting M2-like polarization of tumor associated macrophages. Oncotarget 2015, 6, 36441-36455. [PubMed]

27. Caër, C.; Rouault, C.; Le Roy, T.; Poitou, C.; Aron-Wisnewsky, J.; Torcivia, A.; Bichet, J.C.; Clément, K.; Guerre-Millo, M.; André, S. Immune cell-derived cytokines contribute to obesity-related inflammation, fibrogenesis and metabolic deregulation in human adipose tissue. Sci. Rep. 2017, 7, 3000. [CrossRef] [PubMed]

28. Griss, T.; Vincent, E.E.; Egnatchik, R.; Chen, J.; Ma, E.H.; Faubert, B.; Viollet, B.; DeBerardinis, R.J.; Jones, R.G. Metformin Antagonizes Cancer Cell Proliferation by Suppressing Mitochondrial-Dependent Biosynthesis. PLoS Biol. 2015, 13, e1002309. [CrossRef] [PubMed]

29. Cuyàs, E.; Fernández-Arroyo, S.; Alarcón, T.; Lupu, R.; Joven, J.; Menendez, J.A. Germline BRCA1 mutation reprograms breast epithelial cell metabolism towards mitochondrial-dependent biosynthesis: Evidence for metformin-based "starvation" strategies in BRCA1 carriers. Oncotarget 2016, 7, 52974-52992. [CrossRef] [PubMed] 
30. Satapati, S.; Sunny, N.E.; Kucejova, B.; Fu, X.; He, T.T.; Méndez-Lucas, A.; Shelton, J.M.; Perales, J.C.; Browning, J.D.; Burgess, S.C. Elevated TCA cycle function in the pathology of diet-induced hepatic insulin resistance and fatty liver. J. Lipid Res. 2012, 53, 1080-1092. [CrossRef] [PubMed]

31. Satapati, S.; Kucejova, B.; Duarte, J.A.; Fletcher, J.A.; Reynolds, L.; Sunny, N.E.; He, T.; Nair, L.A.; Livingston, K.; Fu, X.; et al. Mitochondrial metabolism mediates oxidative stress and inflammation in fatty liver. J. Clin. Investig. 2015, 125, 4447-4462. [CrossRef] [PubMed]

32. García-Heredia, A.; Riera-Borrull, M.; Fort-Gallifa, I.; Luciano-Mateo, F.; Cabré, N.; Hernández-Aguilera, A.; Joven, J.; Camps, J. Metformin administration induces hepatotoxic effects in paraoxonase-1-deficient mice. Chem. Biol. Interact. 2016, 249, 56-63. [CrossRef] [PubMed]

33. Herman, M.A.; She, P.; Peroni, O.D.; Lynch, C.J.; Kahn, B.B. Adipose tissue branched chain amino acid (BCAA) metabolism modulates circulating BCAA levels. J. Biol. Chem. 2010, 285, 11348-11356. [CrossRef] [PubMed]

34. Green, C.R.; Wallace, M.; Divakaruni, A.S.; Phillips, S.A.; Murphy, A.N.; Ciaraldi, T.P.; Metallo, C.M. Branched-chain amino acid catabolism fuels adipocyte differentiation and lipogenesis. Nat. Chem. Biol. 2016, 12, 15-21. [CrossRef] [PubMed]

35. Karise, I.; Ornellas, F.; Barbosa-da-Silva, S.; Matsuura, C.; del Sol, M.; Aguila, M.B.; Mandarim-de-Lacerda, C.A. Liver and Metformin: Lessons of a fructose diet in mice. Biochim. Open 2017, 4, 19-30. [CrossRef]

36. Cufí, S.; Corominas-Faja, B.; Lopez-Bonet, E.; Bonavia, R.; Pernas, S.; López, I.Á.; Dorca, J.; Martínez, S.; López, N.B.; Fernández, S.D.; et al. Dietary restriction-resistant human tumors harboring the PIK3CA-activating mutation H1047R are sensitive to metformin. Oncotarget 2013, 4, 1484-1495. [CrossRef] [PubMed]

37. López-Otín, C.; Galluzzi, L.; Freije, J.M.; Madeo, F.; Kroemer, G. Metabolic Control of Longevity. Cell 2016, 166, 802-821. [CrossRef] [PubMed]

38. Anisimov, V.N. Metformin: Do we finally have an anti-aging drug? Cell Cycle 2013, 12, 3483-3489. [CrossRef] [PubMed]

39. Joven, J.; Rull, A.; Ferré, N.; Escolà-Gil, J.C.; Marsillach, J.; Coll, B.; Alonso-Villaverde, C.; Aragones, G.; Claria, J.; Camps, J. The results in rodent models of atherosclerosis are not interchangeable: The influence of diet and strain. Atherosclerosis 2007, 195, e85-e92. [CrossRef] [PubMed]

40. Riera-Borrull, M.; Rodríguez-Gallego, E.; Hernández-Aguilera, A.; Luciano, F.; Ras, R.; Cuyàs, E.; Camps, J.; Segura-Carretero, A.; Menendez, J.A.; Joven, J.; et al. Exploring the Process of Energy Generation in Pathophysiology by Targeted Metabolomics: Performance of a Simple and Quantitative Method. J. Am. Soc. Mass Spectrom. 2016, 27, 168-177. [CrossRef] [PubMed]

41. Anisimov, V.N. Metformin for Prevention and Treatment of Colon Cancer: A Reappraisal of Experimental and Clinical Data. Curr. Drug Targets 2016, 17, 439-446. [CrossRef] [PubMed]

42. García-Heredia, A.; Kensicki, E.; Mohney, R.P.; Rull, A.; Triguero, I.; Marsillach, J.; Tormos, C.; Mackness, B.; Mackness, M.; Shih, D.M.; et al. Paraoxonase-1 deficiency is associated with severe liver steatosis in mice fed a high-fat high-cholesterol diet: A metabolomic approach. J. Proteome Res. 2013, 12, 1946-1955. [CrossRef] [PubMed]

43. Joven, J.; Espinel, E.; Rull, A.; Aragonès, G.; Rodríguez-Gallego, E.; Camps, J.; Micol, V.; Herranz-López, M.; Menéndez, J.A.; Borrás, I.; et al. Plant-derived polyphenols regulate expression of miRNA paralogs miR-103/107 and miR-122 and prevent diet-induced fatty liver disease in hyperlipidemic mice. Biochim. Biophys. Acta 2012, 1820, 894-899. [CrossRef] [PubMed]

44. Xia, J.; Sinelnikov, I.V.; Han, B.; Wishart, D.S. MetaboAnalyst 3.0-Making metabolomics more meaningful. Nucleic Acids Res. 2015, 43, W251-W257. [CrossRef] [PubMed]

(C) 2017 by the authors. Licensee MDPI, Basel, Switzerland. This article is an open access article distributed under the terms and conditions of the Creative Commons Attribution (CC BY) license (http:/ / creativecommons.org/licenses/by/4.0/). 